\title{
ON SOME AFFECTIONS OF THE NERVOUS SYSTEM
}

\author{
MET WITH IN ASSOCIATION WITH AN \\ ATTACK OF \\ ENTERIC FEVER
}

BY

\begin{abstract}
JOHN ABERCROMBIE, M.D.Cantab., F.R.C.P., PHYSICIAN TO THE CHARING CROSS HOSPITAL
\end{abstract}

Received Octolser 13th, 1896-Read K'ebruary 9th, 1897.

I PRopose in this paper only to deal with a few of the complications or sequels of enteric fever due to affections of the nervous system. The occasional occurrence of imbecility as a sequel of enteric fever is well known, and is ascribed by Murchison to an anæmic or atrophied state of the brain. It has twice happened to me to see patients admitted into hospital in a state of apparent imbecility after an attack of enteric fever; and as it is a sequel very rarely met with in patients treated in the hospital throughout the whole illness, I came to the conclusion that it was probable that the imbecility was mainly due to the insufficient feeding during the attack which home nursing 
amongst the poor would be sure to entail, and this idea harmonises well with Murchison's view as to the pathology.

The following case seems to support this view. A boy nged 13 was admitted under my care at Charing Cross Hospital on October 14th, 1895, suffering from enteric fever, it being about the eighth day. The attack was a severe one, and for a week after he came in his temperature was almost continuously over $104^{\circ}$; by the thirtieth day his worning temperature was normal, but the evening temperature was never quite satisfactory, and after eight days it began to rise again, and he had an exceedingly severe relapse, lasting four weeks, which was followed a week later by another relapse lasting five days. He was very delirious and noisy when he came in, and then passed into a state of complete mental dulness, taking no notice of anything that went on around him, but resenting any interference, and especially any attempt to feed him; from the day after his admission until November 15th he never spoke, and until a few days before this he showed no sign of uuderstanding anything that was said to him, and hefought so against his food that it had been necessary to feed him through the nose. From October 19th to November 13th nasal feeding was employed, and for the greater part of this time he took absolutely nothing by the mouth; three feeds were given in the twenty-four hours; at first of half a pint each, but this was gradually increased to fifteen ounces. During the relapse he again ceased to speak, and became again apparently imbecile, and as troublesome about his food as before. Nasal feeding was resumed on November 22nd, and not finally abandoned until December 17th, and during this period we had the additional difficulty to contend with that he was sometimes sick just after a feed. His bowels were constipated throughout, and for many weeks he passed everything under him, and lay just where he was placed, with his thighs flexed on his abdomen; he objected to being disturbed at all, and seemed very tender everywhere. When he began to get a little better he gave 
much trouble by biting and eating his sheets, a habit we only broke him of by leaving him between blankets. Just before Christmas, and before he was strong enough to sit up in bed, he begged to be allowed to draw and paint, and he would spend the whole day in his new-found occupation, hardly allowing himself to be interfered with even for food, and certainly not for so trivial an occurrence as the doctor's visit; the sister of the ward was quite distressed at not being able to correct what she considered his breach of good manners, and he did not recover his mental equilibrium till about the middle of January, when his mind was a complete blank as to everything that had passed, and his craze for drawing, in which he displayed very considerable talent, gradually waned, and finally ceased to exist. During this period all his hair came out.

On January 15th he complained that his left foot felt heavy; he had noticed numbness in it and pins and needles for some days, he said, and there was found to be decided foot-drop with increased knee-jerk and some ankle-clonus; subsequently the reaction of degeneration was found in the muscles of the tibialis anticus group, and the leg wasted a little; he was of course already extremely emaciated in consequence of his long illness. There was at no time any loss or alteration of sensation, and he never had any spontaneous pain in it, nor was there ever any muscular tenderness. He left the hospital on May 7th practically well.

There can be but little doubt, I think, that his inental condition was directly due to the difficulty in getting sufficient nourishment into him both during the original attack and during the relapse. At these times his face was quite expressionless, but he had some very slight intelligence, for he would put out his tongue when I came to his bedside; but if I asked him a question or told him to give me his hand, he would put his tongue out again, and his features showed no sign that he had comprehended what was said to him. When well he 
proved to be a boy of considerable intelligence, decidedly above the arerage for his age. The paralysis coming on during convalescence was a decidedly interesting feature in the case. Cases of so-called peripheral neuritis as a sequel of enteric fever have been recorded by Dr. Handford in this country, and Dr. Osler in America; but it is an excessively rare sequel in so young a subject as my patient; though he had a good deal of general hypermsthesia he did not have the condition of tender toes which I think Handford ('Brain,' prrt 42) was the first to describe. My case may be compared with one recorded by Dr. Shore ('St. Barth. Hosp. Reports,' vol. xxiii). His patient was a married woman aged twenty-six ; the paralysis affected the arms, and began about seven weeks after the fever was over. In my case the interval was shorter, but then my patient was much younger, so that it would appear possible that the rule which I believe holds good in diphtheria, viz. the older the patient the more is the onset of paralysis delayed, may also be true of enteric fever. I have once met with an instance of what I think might be called kleptomania. A boy aged eight, during early convalescence from enteric fever, stole a knife from the locker of the patient in the bed adjoining his, and on the following day sold it for a penny to another boy in the ward who had come to his bedside. On being accused of the theft he did not seem able to understand what all the fuss was about, and when he was well he seemed in all respects a very well-behaved boy, and the theft and subsequent sale were of such a barefaced nature that I had no doubt they were the acts of one who at the time was not fully responsible for his deeds. I may add that during the fever he had had an unusual degree of delirium, and he had shown some delusions.

Rigors may mean the supervention of peritonitis or the occurrence of perforation, but, as was pointed out by Dr. Gee ('St. Barth. Hosp. Reports,' vol. $x$ ), they may have no such grave significance. I have met with several in- 
stances bearing out the truth of his observation. As a rule, when due to constipation or any form of simple intestinal irritation, they occur late in the course of the disease ; one patient under my care had two rigors, with an interval of one day between them, more than two months after her admission into the hospital; the case had been one of great interest, as the patient had an attack of acute mania during the primary fever, but she had been quite convalescent for some time before the rigors. The temperature may run up very high ; I have known it to reach $106^{\circ}$, and subside almost as rapidly after the bowels have been relieved by enema. As a rule it may be said that the earlier the rigor occurs in the course of the disease, the greater is the probability of its being due to perforation or peritonitis; but I have known a rigor on the twenty-second day of the illness to be dependent upon constipation. With the exception of the patient whose case I allude to directly, all the rigors of this kind I have met with have occurred in women, and Dr. Gee's patients were also women.

Dr. Osler has written the most complete paper on this subject that I have yet met with, in the 'Johns Hopkins Hospital Reports,'. vol. v, but curiously enough he does not inention the possibility of constipation or intestinal irritation being a cause of rigors. In some of his cases the rigors appeared to be due to the injudicious use of some of the modern antipyretics; of this group I have no personal experience, but in two of his cases the rigors were associated with venous thrombosis, and in this connection I might mention a case to which I shall allude more fully in the latter part of this paper. Suffice it here to say that my patient had eight rigors in the course of his illness; the first occurred on the thirtieth day of his illness, and on the second day of the onset of his first relapse, at a time when, as Osler shows, rigors are not very uncommon. His second, third, fourth, and fifth rigors occurred during his second relapse on the sixtyeighth, sixty-ninth, seventieth, and seventy-first days of 
his illness, and a few days after thrombosis had occurred in his left femoral vein, the right having been affected some ten days earlier. That the rigors were closely associated with the vein trouble was, I think, proved by the fact that during these few days a tender swelling about the middle of his left calf made its appearance, and exactly in the course of the short saphenous vein. His sixth rigor occurred on the seventy-fifth day, and was probably due to intestinal irritation; the patient ascribed it to his having remained a very long time on the slipper in the expectation that his bowels would be more completely relieved than they had been. The seventh and eighth rigors occurred on the eighty-first and eighty-seventh days respectively, and both were apparently due to mental worry, the first being associated with the fact that his night nurse had been taken ill, and he found himself in the hands of a stranger; and the latter occurred exactly one hour after we had told him, in response to a direct question, that the nurse was suffering from enteric fever. In each instance his temperature went up to $103^{\circ}$, and remained high for two days.

On two occasions I have met with convulsions in the course of enteric fever, and as this is not only a very rare occurrence, but the source of great alarm, I shall give the cases in some detail. Both cases were met with in private practice. The first occurred some few years ago in the person of a young married lady, aged twenty, whom I saw in consultation with Dr. J. Henry Philpot. She was confined of her first child on November 3rd, being attended by Dr. Gibbons, who has assured me that the labour was in all respects normal, and that she went on well until November 20th, when she complained of headache, and he took her temperature and found it to be $104^{\circ}$. She was at the time allowed to be on the couch every day. He ordered her back to bed, and as there was an entire absence of symptoms apart from the headache, the possibility of enteric fever was 
present in his mind. On November 26th characteristic spots made their appearance, and he then transferred her to our care. Her temperature remained very high for more than the first week, -only once, in fact, failing to reach $104^{\circ}$. In the course of the second week there was marked diarrhœa, which was, however, controlled, and meteorism appeared early and was very pronounced, and very great difficulty was experienced in getting her to take her nourishment. On December 5th, at 10.45 p.m., she had a convulsion lasting two minutes, and later on that night at 1.30 a.m. she had a second. When I arrived I found that Dr. Philpot had already drawn off some urine and examined it, finding a trace of albumen, not more than about one thirtieth; her temperature at that time did not exceed $101^{\circ}$, and had not been affected by the convulsions. Her pulse was somewhat hard; the heart-sounds were clear, the first sound being especially sharp. We could arrive at no conclusion as to the cause of the convulsions, except that we did not regard them as uræmic. We gave her chloral hydrate gr. $\mathrm{xx}$ at once, and ordered a draught containing ammon. bromide gr. $x \times x$ to be given every three hours. Later on that day she seemed in no way the worse for the convulsions, nor could we discover anything that threw any light on their causation. She was very ill of course, but she had no really unfavorable symptom. She was taking her nourishment very badly, and was being partly fed by means of nutrient enemata, and she had for a day or two had retention of urine, necessitating the use of a catheter. The bowels were acting every day. Next day, at 3.15 p.m., i. e. about thirty-eight hours after the second convulsion, she had a third, after which the chloral was repeated, and at 9.20 p.m. she had a fourth, which lasted three minutes, and was considered by the nurses to have been the most severe of all, and after it her temperature went up to $104 \cdot 8^{\circ}$. It was impossible to conceal the fact that the patient was now in a highly critical state. The attack had occurred at a most inopportuue time, viz. before she had recovered from the 
effects of the labour, and the attack had been from the outset decidedly severe; and as we were entirely in the dark as to the causation of the convulsions, we felt that for aught we could tell they might be repeated at any moment. On the other hand, there was no sufficient reason for anything like despair. The patient was young, her previous health had always been excellent, and there was no tendency to any form of cerebral affection in her family. The albumen had disappeared from her urine, and in spite of the extreme difficulty in regard to nourishment, owing to her obstinately refusing to take it, her heart was acting well, the first sound being particularly good for a case of such severity. It seemed to us that the convulsions must be reflex. In infants, as is well known, convulsions are easily induced by a slight intestinal irritation. Our patient was in many respects reduced to the condition of an infant; physically she was very weak,-indeed, she had no muscular power at all. The bowels were acting every day, the motions had always been submitted for our inspection, and we had considered them satisfactory. Still we decided to risk the effect of an enema, though the fear of re-inducing the diarrhœa, which at an earlier stage had been somewhat troublesome, was present to our minds. Accordingly, a glycerine enema was administered, with the result that a large, pultaceons, very offensive stool was evacuated. Her temperature came down to $101^{\circ}$ that night, and the patient had no more convulsions.

The rest of the case I need not further describe, though our anxieties were by no means over with the cessation of the convulsions; she had two recrudescences, and for many days was in a most critical state, but eventually she recovered,-thanks to her good constitution, and to most assiduous nursing, her evening temperature not becoming normal until the sixtieth day.

The second case occurred this summer (1896) in the person of a gentleman whom I saw in consultation with his medical adviser. I have already referred to this 
patient when speaking of the occurrence of rigors. The patient was a German aged thirty-five, who contracted enteric fever whilst convalescing from his second attack of syphilitic myelitis. Nothing noteworthy occurred during the primary attack, which was of no great severity, and lasted about three weeks; in four days' time his temperature began to rise again, and on the second day of his relapse he had, as already mentioned, a rigor; the relapse, which was decidedly severe, lasted until the thirty-fifth day, and six days later, on August 14th, he had a convulsion. From his previous history I had fully, I may say almost confidently, expected that he would develop some paralytic trouble, so I was not surprised when on August 10th he complained that his left leg felt heavy; he had, however, no numbness or tingling in it, nor was there any affection of sensation; so we were able to reassure him as to the condition of his leg. Two days before this he had complained of some bladder irritation, $i$. e. frequency of micturition, but this had been completely relieved by a few doses of an acid mixture, the urine having been found to be alkaline. On August 14th he seemed to be going on well, but he had had some return of his bladder irritation, and his urine contained a little blood and some albumen; it was not, however, smoky. On the previous day he had complained of pain and tenderness in the lower part of the belly on the right side, about an inch and a half above the middle of Poupart's ligament; this had, however, disappeared after a hot fomentation. His temperature was normal, and his bowels were acting every day after an enema; throughout his whole illness he had always required an enema. At 6.10 p.m. this evening whilst on the slipper he had a convulsion, and was unconscious for six or seven minutes; his temperature did not go up. The motion was sufficiently copious, light in colour, partly formed, and moderately offensive. His doctor saw him at about 7.30, and found him very nervous about himself ; his heart's action was very tumultuous, and his pulse could not be counted at the wrist. He passed vOL. LXXX. 
a very wretched night, but when I saw him on the afternoon of the following day his pulse had got back to its usual rate, which was about 120 , and his heart-sounds were clear. Seeing the circumstances in which the convulsion occurred, and in view of my experience in the previous case, I had no hesitation in ascribing the convulsion to intestinal irritation, but I was nevertheless much puzzled at the extreme and persistent perturbation of the heart's action, which had lasted for more than twelve hours. During the next few days he frequently had the bladder irritation, and he also complained a good deal of pain at the old spot on the right side of the abdomen, but he complained most of all of pain in his penis, which for about six days was continuous, and kept him awake at night. There was nothing to be seen the matter with his penis; and as the patient was extremely nervous, we were disposed to think the symptom was of no importance, but his temperature had begun to rise a little, and was always between $99^{\circ}$ and $100^{\circ}$ until August 24th, when he complained that his right leg felt heavy, and on examination we found that it was swollen, and that there was tenderness over the femoral vein. This gave us a clue to his recent symptoms, as phlebitis of the internal pudic vein or of some of its branches would explain the pain and tenderness in his belly, the pain in the penis, the bladder irritation, and the presence of blood in the urine. It was necessary further to revise the opinion we had formed as to the cause of his convulsion, for the passage of a portion of thrombus to the heart gave us a much better explanation of all the symptoms at that time than the one we had been so willing to adopt. This date, August 24th, proved the starting-point of a second relapse of considerable severity, and very prolonged, for it lasted quite a month, and it was during this relapse that four of his rigors occurred, thrombosis of the femoral vein on the left side having supervened on September 5th. His evening temperature became finally normal on the ninetieth day of his illness. 
In one of the six cases of convulsions in connection with enteric fever recorded by Murchison, they were associated with thrombosis of the left femoral vein, but it does not appear that he regarded the association as more than coincidental, and his attention seems to have been solely directed to the question whether the convulsions could or could not be attributed to uræmia. I believe that in the two cases I have reported I have succeeded in tracing the convulsions to their true causes.

(For report of the discussion on this paper, see ' Proceedings of the Royal Medical and Chirurgical Society,' Third Series, vol. ix, p. 57.) 